\title{
Antifouling Eco-Filters for Water Bio-Econtamination ${ }^{\dagger}$
}

\author{
Elisabete R. Silva ${ }^{1,2, *}$, Olga Ferreira ${ }^{1,2}$, Patrícia Rijo ${ }^{3,4}$, João C. Bordado ${ }^{2}$ and Maria J. Calhorda ${ }^{1}$ \\ 1 Centro de Química e Bioquímica (CQB/DQB), Faculdade de Ciências, Universidade de Lisboa, \\ Campo Grande, 1749-016 Lisboa, Portugal; orferreira@fc.ul.pt (O.F.); mjcalhorda@fc.ul.pt (M.J.C.) \\ 2 CERENA, Departamento de Engenharia Química, Instituto Superior Técnico, Universidade de Lisboa, \\ Avenida Rovisco Pais, 1049-001 Lisboa, Portugal; jcbordado@tecnico.ulisboa.pt \\ 3 Research Center for Biosciences \& Health Technologies (CBIOS), Universidade Lusófona de Humanidades \\ e Tecnologias, 1749-024 Lisboa, Portugal; patricia.rijo@ulusofona.pt \\ 4 Instituto de Investigação do Medicamento (iMed.ULisboa), Faculdade de Farmácia, \\ Universidade de Lisboa, 1649-003 Lisboa, Portugal \\ * Correspondence: ersilva@fc.ul.pt; Tel.: +351-217-500-991 \\ + Presented at the 2nd International Electronic Conference on Water Sciences, 16-30 November 2017; \\ Available online: http://sciforum.net/conference/ecws-2.
}

Published: 16 November 2017

\begin{abstract}
Water bio-contamination causes serious environmental and economic penalties and health risks in several applications (e.g., freshwater and seawater circuits). In this work, a nontoxic potential strategy able to control this bioburden through new functional bioactive agents, capable of being tethered in polymeric coatings, is presented. Econea biocide was successfully tethered in a silicone-based coating, further used to coat polymeric substrates and monolithic filters. Coated substrates demonstrated promising antifouling effects after being submerged for more than a year in simulated and real conditions. Furthermore, coated monolithic filters showed auspicious growth inhibition and bacteriostatic behaviour for the S. aureus MRSA bacteria.
\end{abstract}

Keywords: biofouling; tethered biocides; non-release coatings; antifouling coated filters; water purification

\section{Introduction}

Over two-thirds of Earth's surface is covered by water, a vital source for all living organisms, able to provide them with nutrients, as well as transport them to other locations which can offer better conditions for their survival. The progress and sustainability of our society are the most representative examples of this water dependency, from nutrients provision to its own growth and expansion (e.g., maritime transport).

However, ironically, what should be a benefit also becomes one of the biggest causes of problems. The spontaneous colonization by aquatic organisms (e.g., waterborne pathogens such as bacteria, fungi, marine organisms) on submerged surfaces, leading to the formation of biofouling [1], has been associated to serious penalties, particularly on engineering surfaces (e.g., pipes for water supply, swimming pools, desalination units, etc.). It gives rise to the known Industrial Biofouling [2], associated to substantial operational consequences (e.g., efficiency losses up to $5 \%$ in power plants) [3], substrate deterioration or the improper function of devices, resulting in severe economic and environmental penalties. This became of particular alarm on fluid circuits systems, such as water purification and distribution, since such systems promote the contact between water and the biofouling on surfaces. As a result, fluid contamination occurs, which can lead to subsequent serious or even lethal human infections [1-5], becoming a major public health concern.

Efforts have been widely explored to mitigate this bio-contamination [6,7]. Hitherto, the most effective strategy follows a chemical approach. It comprises the direct and/or controlled release of 
toxic substances or disinfectants into the contaminated surface/fluid. In particular, for the removal of microorganisms from fluids, studies have been focused on the development of filter systems (e.g., structured filters) possessing antifouling properties [8,9]. The most common approach is based on the deposition or incorporation of bioactive metal ions or metal oxides (e.g., silver- and copperbased) or even biocides on filter surfaces [9]. However, the major drawback of these approaches is the continuous leaching of those toxic agents into the aquatic environment. Their subsequent accumulation and/or intrinsic ecotoxicity have been associated with serious harmful side-effects [10-12]. Therefore, rigid environmental regulations have been implemented (BPR, Regulation (EU) 528/2012), compromising the permission to use the current or newly available agents.

Recent studies have boosted new non-releasing biocide systems, for instance, antimicrobial polymeric materials [7] and coatings with tethered biocides [13,14]. They have provided evidence that the immobilisation of antifouling agents can lead to more controllable and long-term biocidal activity. However, the killed microorganisms remain on the substrate, thus providing a layer to support new ones, which compromises their biocidal action. Innovative approaches are sought to overcome these limitations. As is known, such non-releasing biocidal active surfaces or coatings combined with structured filters, such as monoliths, for biofouling prevention on submerged surfaces, have not been explored.

In this study, a novel strategy based on the chemical immobilisation of antifouling agents in the most recent foul-release silicone-based coatings was developed [14]. It comprised the development of non-releasing biocidal systems by providing new functional reactive biocides capable of being tethered in those coatings, further used to coat monolithic filters. This novel approach is presented here as a potentially long-lasting and eco-friendly antifouling alternative for biofouling prevention in waterborne systems.

\section{Materials and Methods}

\subsection{Immobilisation of Antifouling Agents in Polymeric Coatings}

Commercial Econea ${ }^{\circledR}$ (provided by Janssen PMP, 98\%) biocide (4-bromo-2-(4-chlorophenyl)-5(trifluoromethyl)-1H-pyrrole-3-carbonitrile) has been selected to be immobilised. It is considered a booster antifouling agent, with high potential to replace toxic antifouling agents, due to its relatively short lifetime (half-lifetime of about $3 \mathrm{~h}$ in seawater), and a wide range of bioactivity, particularly for hard foulants. For the immobilisation of this biocide in polymeric coatings, a prior functionalisation process involving its reaction with a diisocyanate reagent in which the biocide functionalised will have a $-\mathrm{N}=\mathrm{C}=\mathrm{O}$ reactive function, capable of being tethered in different and compatible polymeric matrixes (polyurethane- and silicone-based marine paints, provided by HEMPEL SA) was performed. A detailed description of this process can be found in the recent patent application [14].

The commercial biocide and their functional counterpart were further analysed by Fourier Transform Infrared Spectroscopy (FTIR) (Nicolet Magna FTIR 550 Spectrometer coupled to an attenuate total reflectance unit Smart MiracleTM- Pike Technologies with an individual ZnSe crystal on the $500-4000 \mathrm{~cm}^{-1}$ range with $4 \mathrm{~cm}^{-1}$ resolution) to evaluate their chemical structure, and in the case of the functional biocides, to confirm the $-\mathrm{N}=\mathrm{C}=\mathrm{O}$ functionalisation effectiveness. In the particular case of Econea and in order to better evidence the biocide characteristic FTIR bands, the FTIR spectrum was obtained from an Econea/KBr-prepared waffle.

The $\mathrm{R}-\mathrm{N}=\mathrm{C}=\mathrm{O}$ free content was obtained by a standard adapted procedure from the standard ASTMD2572.

Bioactivity evaluation: prior to the immobilisation of biocides in polymeric coatings, and in order to confirm the bioactivity of the functional biocides (e.g., Econea- $\mathrm{N}=\mathrm{C}=\mathrm{O}$ ), the antibacterial activity of the developed samples was evaluated using the well diffusion method on MuellerHinton agar (MHA). Staphylococcus aureus (ATCC 25923) and Enterococcus faecalis (ATCC 29212) strains were used as model bacteria for the antibacterial assay of biocides. Briefly, $100 \mu \mathrm{L}$ of standardised bacterial strain suspensions, corresponding to a turbidity of $0.5 \mathrm{McF}$ arland, were used 
to inoculate an MHA petri dish, under aseptic conditions. Subsequently, agar wells (diameter $=5.0$ $\mathrm{mm}$ ) were made, filled with $50 \mu \mathrm{L}$ of the test samples, including the negative control (DMSO) and positive control (Vancomycin), and further incubated at $37^{\circ} \mathrm{C}$ for $24 \mathrm{~h}$. The resulting inhibition zones were reported in millimetre $(\mathrm{mm})$. The tests were performed for each sample and strain in triplicate.

Immobilisation of biocides in polymeric coatings: The biocides were added as additives in a silicone marine-based paint (Ref. 87509) generously provided by Hempel A/S. The experimental formulations were developed in the framework of the European FP7 collaborative project FOUL-XSPEL (grant agreement 285552). Conventional methods (e.g., brush) were used for further application, i.e., the coating of substrates.

\subsection{Antifouling Coatings Characterization}

Physical-chemical properties of the developed formulations have been assessed in previous works [15,16], in particular, an eco-toxicity study [17].

\section{Antifouling Assessment}

Proof-of-concept of the coatings of greatest potential with chemically immobilised biocides was provided by an assessment of antifouling performances in simulated (artificial seawater aquarium, $\mathrm{pH} 8.3,23 \pm 1{ }^{\circ} \mathrm{C}$ ) and real field test conditions (Atlantic sea) of coated polymeric substrates (e.g., polyvinyl chloride, PVC). Field tests were performed in relatively static conditions at the Estaleiros Navais de Peniche (ENP) pontoon (coordinates 39 $21^{\prime} 06.6^{\prime \prime} \mathrm{N} \mathrm{9} 9^{\circ} 22^{\prime} 10.5^{\prime \prime} \mathrm{W}$ ), Portugal, in accordance with ASTM D6990 and D3623-78a standards.

\subsection{Coated Monolithic Filters}

Preliminary coating tests of the obtained antifouling/antimicrobial polymeric coating systems were also performed on ceramic filter supports, such as cordierite-based monoliths, by using the conventional dip-coating method. The coated monoliths were further assessed in terms of antimicrobial activity.

\section{Antimicrobial Activity}

In order to assess the antimicrobial activity of the monolithic filters, a time kill test procedure was adapted for the purpose [18]. Briefly, small monolithic samples $(2 \times 2 \times 2 \mathrm{~cm})$ were immersed in a known population of the Methicillin-resistant Staphylococcus aureus (MRSA, CIP 1106760) strain $\left(10^{6} \mathrm{CFU} / \mathrm{mL}\right)$ for $24 \mathrm{~h}$ at $37^{\circ} \mathrm{C}$. The microorganism growth was monitored spectrophotometrically over time (each hour) and quantified by absorbance measurements at OD620 nm. In addition, and in order to address the bactericidal and bacteriostatic properties, aliquots for each set of growth inhibition assays were collected and incubated at $37^{\circ} \mathrm{C}$ for $24 \mathrm{~h}$ in Muller-Hinton medium. Assays were carried out at least in duplicate in independent assays.

\section{Results}

\subsection{Functional Biocide with Linkage Ability into Polymeric Coatings}

Econea biocide was successfully functionalised (conversions as high as 95\%) with a diisocyanate [14,17], acquiring the $-\mathrm{N}=\mathrm{C}=\mathrm{O}$ functionality and thus the covalent linkage ability for a compatible polymeric matrix such as silicone-based paints. FTIR spectra of the new functional biocide (Econea-NCO) confirmed that their structure was not modified and the functional group was successfully attached to the expected bridging point (Figure 1). The $-\mathrm{N}=\mathrm{C}=\mathrm{O}$ functionality of the functional Econea-NCO was revealed by the appearance of the new band ranging from 2327 $\mathrm{cm}^{-1}$ to $2144 \mathrm{~cm}^{-1}$, which is a characteristic peak of free NCO [19]. This $-\mathrm{N}=\mathrm{C}=\mathrm{O}$ characteristic band also partially overlaps with the band attributed to the structural nitrile $(-\mathrm{C} \equiv \mathrm{N})$ functional group of the Econea biocide (Table 1). 


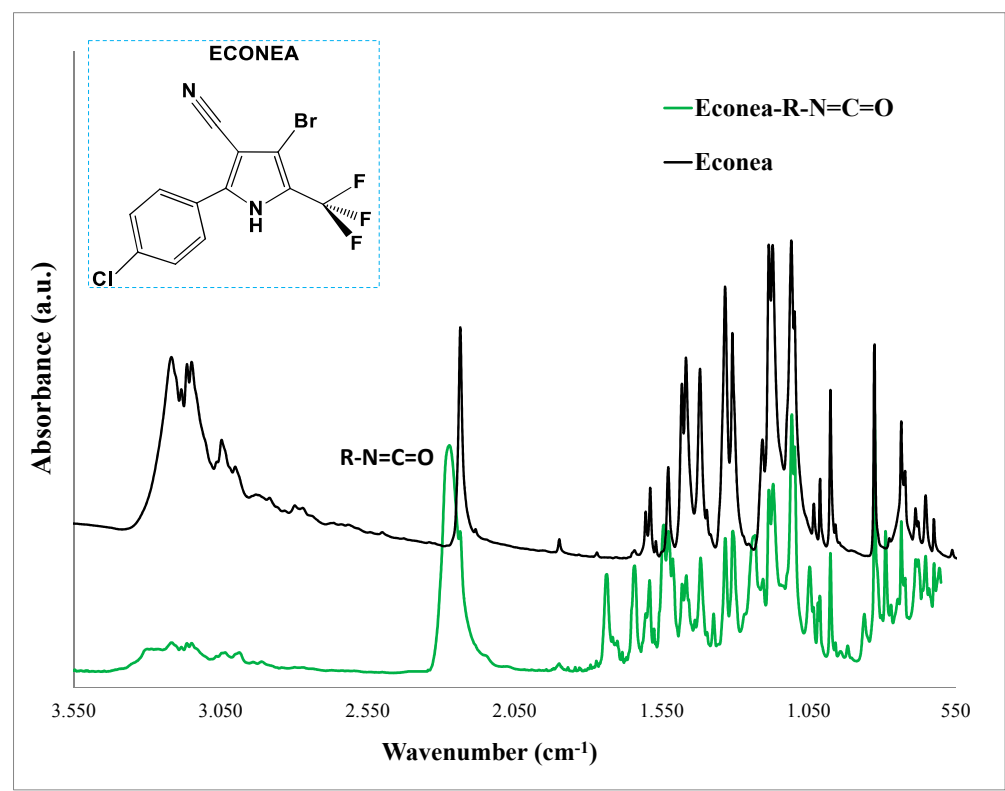

Figure 1. FTIR spectra of Econea and its functional counterpart, Econea-R-N $=\mathrm{C}=\mathrm{O}$.

Table 1. Main obtained bands from infrared spectra (FTIR) analysis of Econea biocide and its functional counterpart Econea-R-N $=\mathrm{C}=\mathrm{O}$.

\begin{tabular}{|c|c|}
\hline \multicolumn{2}{|c|}{ Econea Biocide } \\
\hline Main characteristic bands & Attributed group \\
\hline Group of intense broad bands: $3357-2852 \mathrm{~cm}^{-1}$ & Amines, amides, $\mathrm{O}-\mathrm{H}$ bond, $\mathrm{H}$ \\
\hline $\begin{array}{l}\text { Intense narrow band: } 2260-2152 \mathrm{~cm}^{-1} \\
\text { Maximum at: } 2235 \mathrm{~cm}^{-1}\end{array}$ & Nitrile, $-\mathrm{C} \equiv \mathrm{N}$ \\
\hline Band $1290-1335 \mathrm{~cm}^{-1}$ & Aromatic amine \\
\hline Double intense bands: $1110-1180 \mathrm{~cm}^{-1}$ & CF3 \\
\hline Narrow band with a maximum at $827 \mathrm{~cm}^{-1}$ & $\mathrm{C}-\mathrm{Cl}$ (substituted benzene) \\
\hline \multicolumn{2}{|c|}{ Econea-R-N = C = O (Econea-NCO, Functionalised) } \\
\hline $\begin{array}{l}\text { Intense broad band: } 2327-2144 \mathrm{~cm}^{-1} \\
\text { Maximum at: } 2254 \mathrm{~cm}^{-1} \mathrm{e} 2237 \mathrm{~cm}^{-1}\end{array}$ & $\begin{array}{c}\text { Assigned to }-\mathrm{N}=\mathrm{C}=\mathrm{O} \text { together with Nitrile, } \\
-\mathrm{C} \equiv \mathrm{N}\end{array}$ \\
\hline Narrow band with a maximum at $815 \mathrm{~cm}^{-1}$ & $\mathrm{C}-\mathrm{Cl}$ (substituted benzene) \\
\hline Double intense bands: $1110-1180 \mathrm{~cm}^{-1}$ & CF3 \\
\hline
\end{tabular}

On the other hand, an NCO content of $9 \pm 2 \mathrm{wt}$. \% was obtained for the Econea-NCO, showing that one NCO group may be incorporated in the biocide structure. Deviations in the NCO content are associated with the presence of impurities and moisture, which is impossible to remove completely during the preparation procedure. Moisture, in particular, is highly reactive with the NCO group. Therefore, a limited amount is expected to react with free NCO, reducing its content and reactivity.

\section{Bioactivity Evaluation of Biocides}

Bioactivity assessment of the Econea and functional Econea-NCO biocides (Figure 2, Table 2) showed that for the tested bacteria both biocides possess antimicrobial activity. 


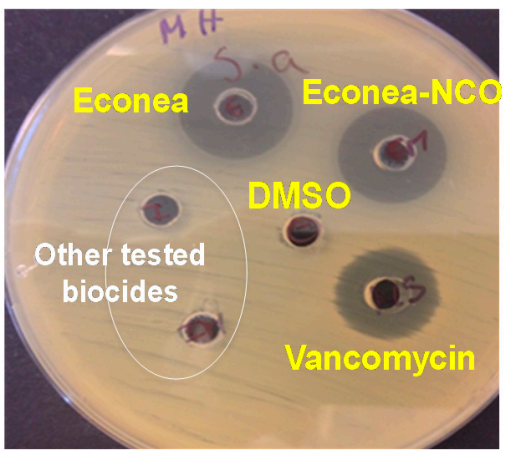

Figure 2. Representative well diffusion test for the assessment of the antimicrobial activity of Econea biocide and its functional counterpart (Econea-NCO), against Staphylococcus aureus. Dimethyl sulfoxide (DMSO) was used as the negative control and Vancomycin as the positive control.

Table 2. Antimicrobial activity of the Econea biocide and its functionalised counterpart against Gram-positive bacteria.

\begin{tabular}{ccc}
\hline Biocides & $\begin{array}{c}\text { Enterococcus faecalis } \\
(\mathbf{m m})\end{array}$ & $\begin{array}{c}\text { Staphylococcus aureus } \\
(\mathbf{m m})\end{array}$ \\
\hline Econea & 20 & 17 \\
Econea-R-NCO & 21 & 17 \\
DMSO (negative control) & 5 & 5 \\
\hline
\end{tabular}

\subsection{Antifouling Assessment}

Proof-of-concept of the coatings of greatest potential with chemically immobilised or tethered Econea biocide was provided by an assessment of antifouling performances in simulated conditions (aquarium). Figure 3 shows representative coated PVC substrates $(6 \times 4 \mathrm{~cm})$ after submersion in an artificial seawater aquarium for more than a year (1.5 years). Nonetheless, and in order to confirm the behaviour of the above-mentioned formulations, in the hardest or most aggressive conditions in terms of biofouling formation promotion, real field tests have been performed on coated PVC substrates $(10 \times 10 \mathrm{~cm})$ (Figure 4$)$.

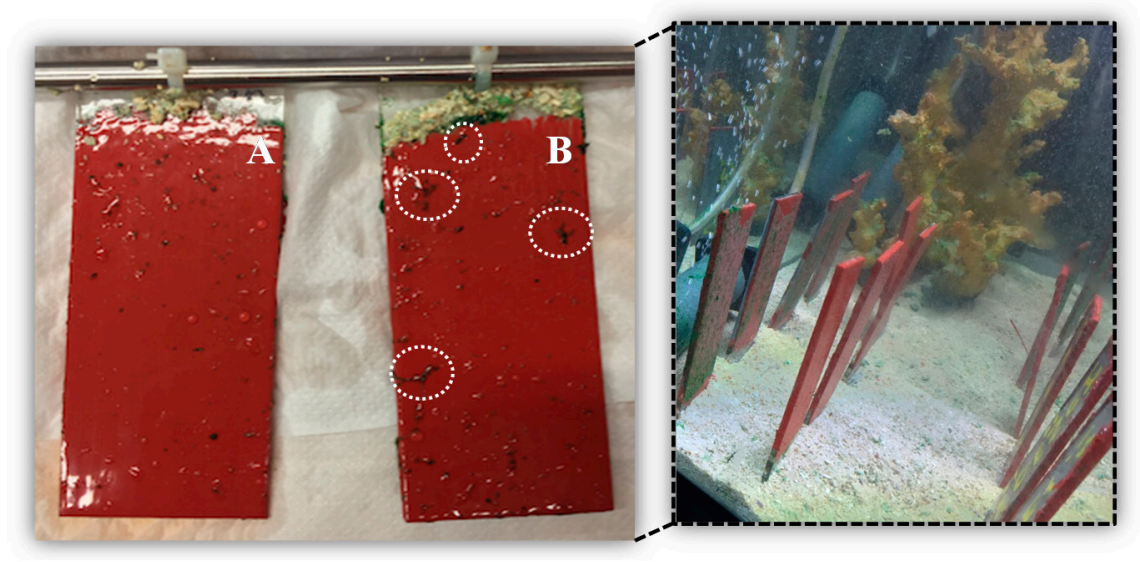

Figure 3. Representative Silicone-based coatings with immobilised Econea biocide (<0.6 wt. \%) (A) and respective Reference $(\mathbf{B})$ without biocide after 1.5 years in an artificial seawater aquarium. 

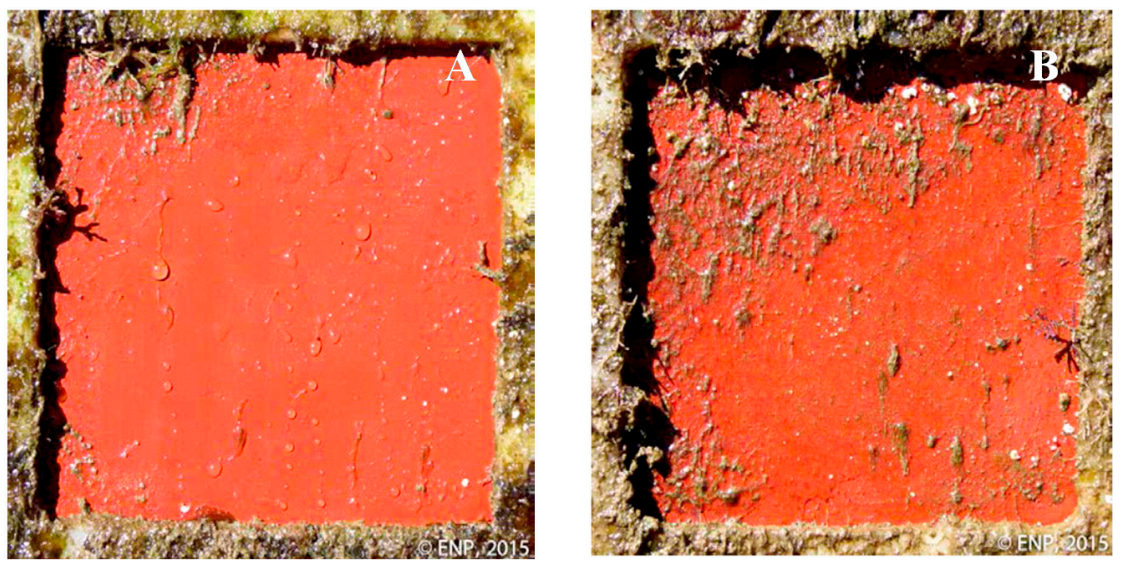

Figure 4. Silicone-based coatings with immobilised Econea biocide $(<0.6 \mathrm{wt}$. \%) (A) and reference (B) without biocide after 45 weeks (about 11 months) submerged in Atlantic sea at the pontoon of Estaleiros Navais de Peniche (ENP), SA, Portugal. Photos generously provided by ENP.

\subsection{Antimicrobial Activity of Coated Monolithic Filters}

Cordierite monolithic filters have been coated for the first time with the prepared non-release antifouling/antimicrobial polymeric systems. Uniform and well adhered polymeric films were obtained (Figure 5), allowing us to proceed with the first antimicrobial tests, i.e., analysis of the effect of coatings on the structured support on the bacterial growth over time, performed for the $S$. aureus MRSA strain (Figures 6 and 7).

The bactericidal and bacteriostatic properties of the coated filters have also been evaluated by performing incubation of aliquots obtained from each growth inhibition assay (data not shown).

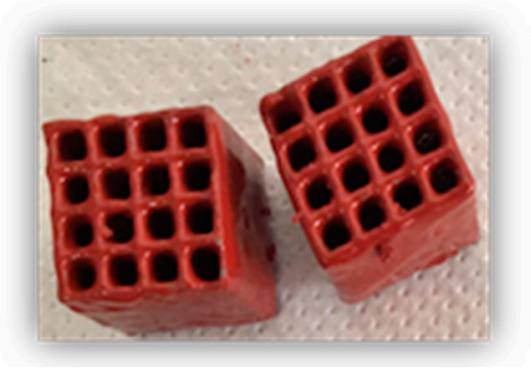

Figure 5. Ceramic monolithic filter (200 cpsi) coated with a silicone-based coating containing tethered Econea $(<0.6$ wt. \%).

\section{S. aureus MRSA Uncoated Monolith Coated Monolith}

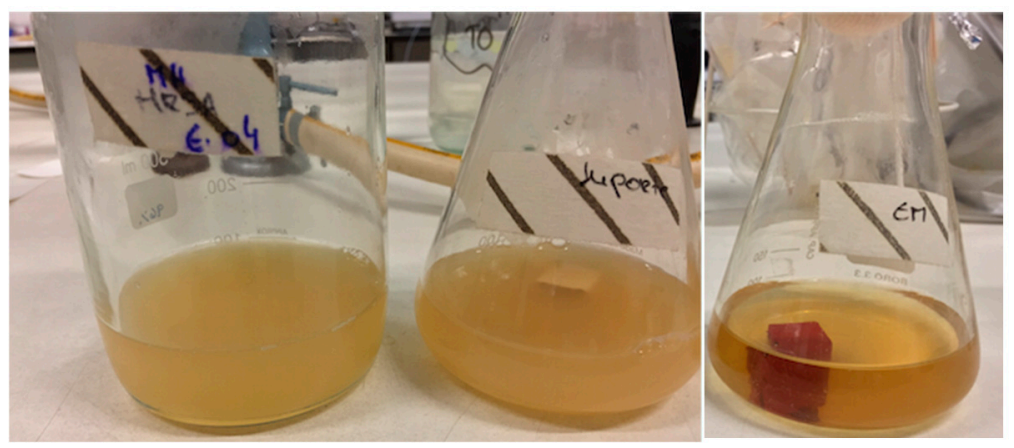

Figure 6. Illustration of the growth inhibition behaviour on the bacterial strain S. aureus MRSA CIP 106760 culture for the uncoated and coated monolithic filter with a silicone-based coating containing tethered Econea biocide (<0.6 wt. \%). 


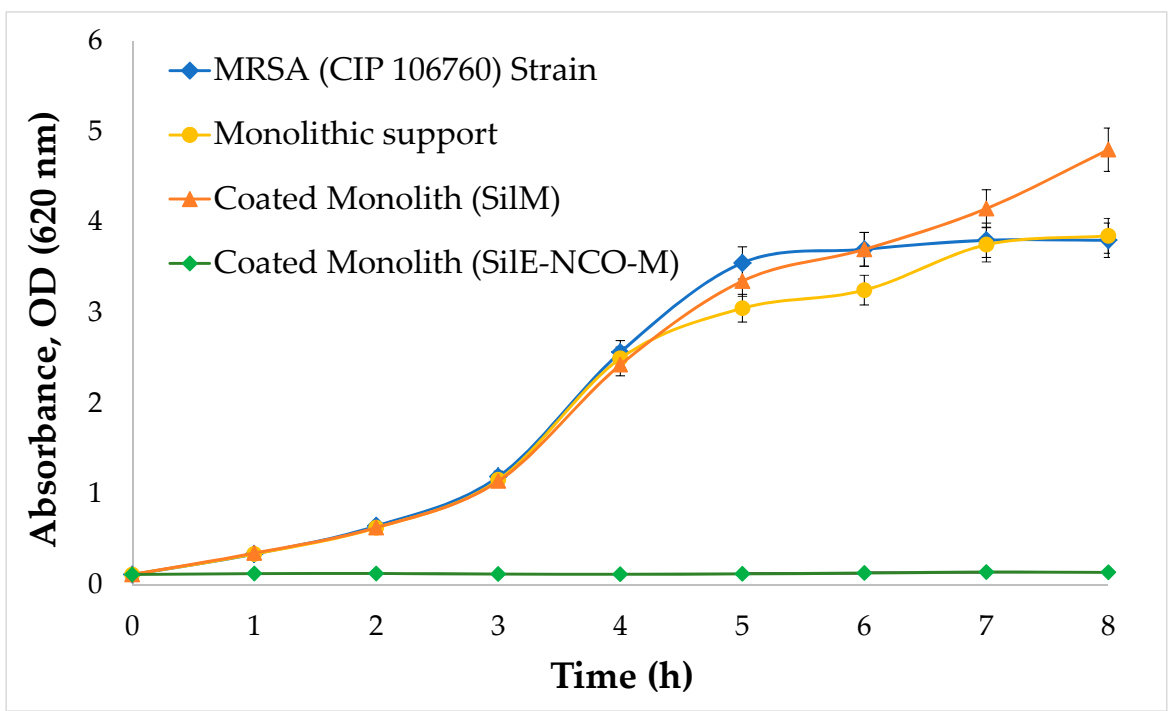

Figure 7. Growth inhibition behaviour of the bacterial strain S. aureus MRSA CIP 106760 for the uncoated and coated monolithic filters: SilM - coated with a silicone (PDMS)-based coating and SilE-NCO-M - coated with a silicone-based coating containing tethered Econea biocide $(<0.6 \mathrm{wt}$. \%).

\section{Discussions}

A recently developed functionalisation process [14] for bioactive agents has been used for the Econea biocide functionalisation with an isocyanate reactive functionality.

FTIR spectra analysis revealed the presence of this reactive function in the biocide spectra, confirming that its structure was not modified and that the isocyanate functional group (band range: $2327-2144 \mathrm{~cm}^{-1}$ ) was successfully attached to the expected bridging point of biocide structure $(-\mathrm{NH})$. The determined NCO contents of the obtained functional Econea (Econea-NCO) is in accordance with the expected degree of bridging point substitution $(-\mathrm{NH})$ with the isocyanate functional group.

Bioactivity assessment of the Econea and functional Econea evidenced antimicrobial activity, particularly against $S$. aureus and E. faecalis bacteria, suggesting that the biocide properties were not significantly affected by the functionalisation process.

The efficacy of this immobilisation strategy was further evaluated by the tethering of Econea antifouling agents in polymeric matrices, such as a silicone marine-based coating. The immobilisation effectiveness has been confirmed in previous works [17], where an eco-toxicity study performed in accordance with the European Standards, and for leaching waters obtained from coatings containing the immobilised biocide, allowed the classification of those coating formulations as non-toxic for the environment. In addition, the developed non-release siliconebased formulation appears to also promote a better anticorrosion protection when compared to its reference counterpart without biocide [16].

The antifouling behaviour of the obtained antifouling silicone-based coatings at simulated conditions (Figure 3), suggested that the coating formulation containing tethered Econea (A) can provide a better antifouling effect than its reference counterpart without biocide (B), since for this last formulation more and bigger spots of biofouling formation were found on the coated substrate surface after an immersion period of more than a year.

Furthermore, and at real conditions (Atlantic seawater), promising antifouling effects were obtained for the non-releasing antifouling coating (A), which corroborated with the tests at simulated conditions. The coated substrate (A) remained clean after 45 weeks (about 11 months) submerged in Atlantic sea.

In the second stage of this work, and aiming to combine these non-releasing biocidal active coatings with a structured filter for the bio-decontamination of waterborne systems, the best nontoxic Econea-based coating was used to coat cordierite monoliths. The first antimicrobial assays performed on those coated monoliths against the S. aureus MRSA CIP 106760 strain showed 
auspicious inhibition effects on the bacteria growth. Complete growth inhibition was observed on a monolithic filter coated with a silicone-based coating containing tethered Econea (SilE-NCO-M) when compared with an uncoated filter (Figures 6 and 7) or even with a coated filter with the silicone coating reference (SilM) (Figure 7). Also, an S. aureus MRSA growth increase on the silicone-coated monolith (SilM) was observed. This behaviour was also found by others [20,21], particularly on functionalised silicone- or polydimethylsiloxane (PDMS)-based coated surfaces. It can be associated with damages on the major PDMS-based coatings original properties (e.g. wettability) [15], provided by the tethering of functional compounds in the polymeric structure of the coating.

After the bacteria inhibition assays, aliquots of bacteria mediums were incubated in order to address the Bactericidal and Bacteriostatic properties of the coated monoliths. After the incubation, bacteria grown freely, and have shown a growth behaviour similar to the bacterial strain S. aureus culture (data not shown). These results confirm a bacteriostatic behaviour for all tested coated monoliths, meaning that the previously found bacteria growth inhibition in the medium containing the coated monolith (SilE-NCO-M), with the non-release Econea silicone-based coating, prevents the formation of the biofilm rather than killing the bacteria. This behaviour is desirable since it minimises the selective pressure on bacteria to evolve treatment resistance.

\section{Conclusions}

The developed non-toxic antifouling strategy based on the tethering of antifouling agents, such as Econea biocide, in polymeric protective coatings, is able to provide non-release biocidal coatings acting by contact, thus avoiding the release of the biocide into the environment or aqueous environment. This proves to be a potential environmentally friendly alternative for the protection of filter surfaces, and therefore for the purification of waterborne systems where they are applied. This approach also proved to be capable of providing a longer-lasting cleaning effect than the conventional strategies that release toxic agents.

The auspicious antimicrobial and bacteriostatic behaviour achieved for coated monolithic filters with a silicone-based coating containing tethered Econea biocide is, undoubtedly, a key result for further research in the field, in particular for the water bio-contamination burden, which still requires much work to overcome.

Acknowledgments: The authors are thankful for the collaboration of HEMPEL A/S, and the support provided by Fundação para a Ciência e a Tecnologia (FCT) through UID/MULTI/00612/2013 and by the FP7 FOUL-XSPEL Project, Grant Agreement No. 285552. E.R. Silva and O. Ferreira are also grateful for the financial support from FCT, Post-Doc fellowship SFRH/BPD/88135/2012 and Grant PD/BD/128370/2017, respectively.

Author Contributions: The research work presented in this paper was carried out with the collaboration of all authors. Specifically, Elisabete R. Silva conceived and designed the experiments; Olga Ferreira performed the experiments; Elisabete R. Silva, Olga Ferreira, and Patrícia Rijo analysed the data; Maria J. Calhorda and João C. Bordado contributed with reagents/materials/analysis tools; Elisabete R. Silva wrote the paper.

Conflicts of Interest: The authors declare no conflict of interest. The founding sponsors had no role in the design of the study; in the collection, analyses, or interpretation of data; in the writing of the manuscript, and in the decision to publish the results.

\section{References}

1. Flemming, H.C. Microbial biofouling: Unsolved problems, insufficient approaches, and possible solutions. In Biofilm Highlights, 1st ed.; Flemming, H.C., Wingender, J., Szewzyk, U., Eds.; Springer: Berlin/Heidelberg, Germany, 2011; Series on Biofilms Volume 5, pp. 81-109, ISBN 978-3-642-19940-0.

2. Bott, T.R. Industrial Biofouling, 1st ed.; Elsevier: Oxford, UK, 2011; pp. 1-199, ISBN 978-0-444-53224-4.

3. Chan, J.; Wong, S. Biofouling Types, Impact and Anti-Fouling, 1st ed.; Nova Science Publishers: New York, NY, USA, 2010; pp. 65-322, ISBN 978-1-60876-501-0.

4. Parr, A.; Whitney, E.A.; Berkelman, R.L. Legionellosis on the rise: A review of guidelines for prevention in the United States. J. Public Health Manag. Pract. 2015, 21, 17-26. 
5. Viazis, S.; Diez-Gonzalez, F. Enterohemorrhagic Escherichia coli: The twentieth century's emerging foodborne pathogen: A review. In Advances in Agronomy, 1st ed.; Sparks, D.L., Ed.; Elsevier Academic Press: San Diego, CA, USA, 2011; Volume 111, pp. 1-50, ISBN 978-0-12-387689-8.

6. Banerjee, I.; Pangule, R.C.; Kane, R.S. Antifouling coatings: Recent developments in the design of surfaces that prevent fouling by proteins, bacteria, and marine organisms. Adv. Mater. 2011, 23, 690-718.

7. Munõz-Bonilla, A.; Fernández-García, M. Polymeric materials with antimicrobial activity. Prog. Polym. Sci. 2012, 37, 281-339.

8. Woo, M.; Lee, J.; Rho, S.; Ulmer, K.; Welch, J.C.; Wu, C.Y.; Song, L.; Baney, R.H. Evaluation of the Performance of Dialdehyde Cellulose Filters against airborne and waterborne Bacteria and Viruses. Ind. Eng. Chem. Res. 2011, 50, 11636-11643.

9. Jain, P.; Pradeep, T. Potential of silver nanoparticles-coated polyurethane foam as an antibacterial water filter. Biotechnol. Bioeng. 2005, 90, 59-63.

10. Senjen, R.; Illuminato, I. Nano \& Biocidal Silver: Extreme Germ Killers Present a Growing Threat to Public Health; Friends of the Earth Australia: Victoria, Australia, 2009.

11. Andrew, C.S.; Shaw, H.; Vicki, R.; Alwyn, H. Review of antimicrobial resistance in the environment and its relevance to environmental regulators. Front. Microbiol. 2016, 7, 1-22.

12. Guardiola, F.A.; Cuesta, A.; Meseguerand, J.; Esteban, M.A. Risks of using antifouling biocides in aquaculture. Int. J. Mol. Sci. 2012, 13, 1541-1560.

13. Kugel, A.; Stafslien, S.; Chisholm, B.J. Antimicrobial coatings produced by "tethering" biocides to the coating matrix: A comprehensive review. Prog. Polym. Sci. 2011, 72, 222-252.

14. Silva, E.R.; Ferreira, O.; Bordado, J.C. Functionalization Process for Biocide Immobilization in Polymeric Matrices. Patent Application, WO2016/093719A1, 2016.

15. Tulcidas, A.V.; Bayon, R.; Igartua, A.; Bordado, J.C.; Olsen, S.M.; Silva, E.R. Friction reduction on recent non-releasing biocidal coatings by a newly designed friction test rig. Tribol. Int. 2015, 91, 140-150.

16. Kiosidou, E.D.; Karantonis, A.; Pantelis, D.I.; Silva, E.R.; Bordado, J.C.M. Rust morphology characterization of silicone based marine antifouling paints after salt spray test on scribed specimens. J. Coat. Technol. Res. 2017, 14, 333-345.

17. Silva, E.R.; Ferreira, O.; Tulcidas, A.V.; Bayon, R.; Igartua, A. Non-releasing biocidal coatings: A new ecofriendly strategy to prevent marine biofouling. In Proceedings of the Shipping in Changing Climates Conference, Glasgow, Scotland, UK, 24-26 November 2015; Volume 2, pp. 307-317.

18. Siopa, F.; Figueiredo, T.; Frade, R.F.M.; Neto, I.; Meirinhos, A.; Reis, C.P.; Sobral, R.G.; Afonso, C.A.M.; Rijo, P. Choline-based ionic liquids: Improvement of antimicrobial activity. Chem. Sel. 2016, 1, 5909-5916.

19. Silverstein, R.M.; Webster, F.X.; Kiemle, D.J. Infrared Spectroscopy. In Spectrometric Identification of Organic Compounds, 7th ed.; Brennan, D., Yee, J., Robichaud, S.W., Eds.; John Wiley \& Sons, Inc.; New York, NY, USA, 2005; pp. 72-126, ISBN 0-471-39362-2.

20. Magennis, E.P.; Hook, A.L.; Williams, P.; Alexander, M.R. Making silicone rubber highly resistant to bacterial attachment using thiol-ene grafting. ACS Appl. Mater. Interfaces 2016, 8, 30780-30787.

21. Cappitelli, F.; Sorlini, C. Microorganisms attack synthetic polymers in items representing our cultural heritage. Appl. Environ. Microbiol. 2008, 74, 564-569.

(C) 2018 by the authors. Licensee MDPI, Basel, Switzerland. This article is an open access article distributed under the terms and conditions of the Creative Commons Attribution (CC BY) license (http://creativecommons.org/licenses/by/4.0/). 